of compounds is extensive and ranges over aminoacids and amines, dinitrophenyl-aminoacids, dimethylamino-naphthalenesulphonyl, iodoaminoacids, sugars, ketoacids, phenolic acids, plant phenols and tannins, purines, pyrimidines and their derivatives, barbiturates, alkaloids, steroids, lipids, phospholipids, several pigments, imidazoles, catecholomines inorganic ions, and guanidines. It is a pity that the last group does not include the chromatography of biguanides which are being increasingly and extensively utilized in various fields.

The book can be recommended as a standard and highly useful laboratory text-book despite the inclusion of a chapter on 'Models for Macromolecules, Nucleic acids and Proteins'; the chapter may be useful otherwise, but is totally irrelevant to chromatographic techniques.

\section{Standardization in Immunofluorescence}

Edited by E. J. Holborow (Assisted by W. D. Brighton, G. SANDer and C. E. D. TAYlor). Pp. xv. +282 . Oxford and Edinburgh: Blackwell Scientific Publications, 1970. $75 \mathrm{~s}$.

Immunofluorescent techniques-initiated by $\mathrm{A}$. H. Coons in 1941 - have made enormous strides in the last thirty years in elucidating location of antigens and antibodies and their reactions in tissues. As is usual with most scientific techniques, concise quantitative assay follows originally primarily qualitative determinations. Such advances require meticulous attention in standardization in respect of both reagents and techniques. With numerous immunological laboratories utilizing fluorescent techniques it is essential that universally accepted standards be employed particularly because some commercial products can prove to be more equivalent than others. With such aims in mind an International Workshop of Standardization in Immunofluorescence was held in Florence in 1967, and this was followed by a Round Table Conference (in London in 1968) which was held under the auspices of the Permanent Section for Microbiological Standardization of the International Association of Microbiological Societies. The contributions of the members of these two conferences and the various discussions have now been published in this book.

The overall range covered is impressive but only few examples can be given: Fluorochromes and their labelling, problems in the fields of antisera and conjugates-preparation, assessment and titration-microscopy, and the use of substrates. The versatility of the immunofluorescent method is elucidated effectively. The book can be recommended not only because of the comparatively up-to-date information given but particularly because of the numerous points discussed and the intellectual stimuli it is bound to provide for workers in the field.

\section{Diagnosis and Drug Treatments of Psychiatric Disorders}

By Donald F Klein and John M. Davis. Pp. 480. Baltimore: Williams and Wilkins. Edinburgh and London: E. \& S. Livingstone, 1969. £5 11s.

A lull in the tempo of psychopharmacological progress has given two Americans, Dr Donald Klein, a Director of Psychiatric Research, and Dr John Davis, a clinical pharmacologist, an opportunity of reviewing, assessing and actually recommending treatment regimens in psychiatry. They have produced a book which is a reasonable mixture of the academic and the clinical, and in so doing, have avoided, on the one hand, the pitfalls of pharmacological obscurity and holistic psychiatric theorizing on the other. Apart from the first few chapters their book is, in fact, a model of the sober empirical approach to psychopharmacology.

Some initial unevenness is due to the fact that Klein and Davis have cast their net too wide: they aim to reach not only medical students, general practitioners and psychiatrists, but also such non-medical professions as social workers, psychologists, educators and religious counsellors. It can be unhesitatingly recommended to the potential medical audience, but its value to others is minimal.

When dealing with attitudes to medication the authors introduce such speculative notions that patients "identify the drug with the dominant parent'; and the section on the organic psychoses omits any reference to the schizophrenialike psychosis of epilepsy. But the authors really get into their stride in Chapter 4 with their excellent review of antipsychotic drug literature followed by recommendations for the treatment of schizophrenia. Then comes the best part of the book in the chapters reviewing the literature, the diagnosis and the treatment of the affective disorders. There are useful sections on the minor tranquillizers and their use in the treatment of the psychoneuroses and personality disorders. And finally, a useful and stimulating critique of drug treatment studies in general: the last chapter being concerned with the action of psychotropic drugs on various clinical groupings in which the authors constantly endeavour to explore further avenues of research, point out the limitations of drug trials and generally provoke thought on improviding methods and techniques. Extensive reference lists follow each chapter, there is an adequate index, and most important of all, a well organized glossary of trade and manufacturers' names.

In spite of the occasional unfamiliar psychiatric terminology this book is the best on the market for the practising psychiatrist. 